\title{
Enhanced Numerical Modeling of HgCdTe Long Wavelength Infrared Radiation High Operating Temperature Non-equilibrium $\mathrm{P}^{+} v(\pi) \mathrm{N}^{+}$Photodiodes
}

\author{
KRZYSZTOF JÓŹWIKOWSKI (i] ${ }^{1,3}$ and ALINA JÓŹWIKOWSKA ${ }^{2}$ \\ 1.-Institute of Applied Physics, Military University of Technology, Gen. Urbanowicza 2 St., \\ 00-908 Warsaw, Poland. 2.-Faculty of Applied Informatics and Mathematics, Warsaw University \\ of Life Science SGGW, Nowoursynowska 166 St., 02-787 Warsaw, Poland. 3.-e-mail: \\ krzysztof.jozwikowski@wat.edu.pl
}

Using our computer programs, numerical simulations of photoelectric and fluctuating phenomena were carried out in diode structures of the $\mathrm{CdHgTe}$ mesa in the $\mathrm{P}^{+} v(\pi) \mathrm{N}^{+}$configuration operating at $230 \mathrm{~K}$ and $300 \mathrm{~K}$. These phenomena were analyzed in structures where additional energy barriers at the absorber boundary were applied. Exclusion and extraction of charge carriers in the absorber area after biasing the structures with reverse voltage reduces their concentration by more than an order of magnitude. Reduction of carrier concentration has a positive effect on the increase of the absorption coefficient due to reduction of the Burstein-Moss effect, increases the resistance and electro-optical gain, and effectively suppresses generation and thermal recombination. It is possible to obtain $70 \%$ of quantum efficiency in biased photodiodes. It was shown that a non-equilibrium long-wave photodiode working at room temperature can have a normalized detectivity of over $10^{9} \mathrm{cmHZ}^{1 / 2} \mathrm{~W}^{-1}$ for radiation with $10.6 \mu \mathrm{m}$ wavelength. The results of our calculations and their analysis are illustrated by numerous figures.

Key words: LWIR HOT HgCdTe photodiodes, two barrier detectors, G-R mechanisms, exclusion and extraction effect

\section{INTRODUCTION}

In recent years we have been observing the development of both technological and theoretical research on long-wave infrared radiation (LWIR) detectors operating at temperatures of 200 $300 \mathrm{~K}^{1-11}$ These detectors, called high operating temperature (HOT) detectors, achieve quite high sensitivity and detectivity, which enables their use without the need for cryogenic cooling. Their responsivity and quantum efficiency are, however, limited by the minority carrier diffusion length and the absorber thickness for a given wavelength. High thermal generation and recombination are the causes of high generation-recombination $(\mathrm{G}-\mathrm{R})$

(Received November 29, 2018; accepted April 30, 2019;

published online May 16, 2019) noise. These are the reasons why the performance of conventional $p-n$ junction LWIR HgCdTe photovoltaic detectors operating at near room temperature is very poor. These problems can be significantly reduced by using the phenomenon of extraction and exclusion of charge carriers in the absorber's area. ${ }^{12-14}$ This can be achieved under significant polarization of the $\mathrm{P}^{+} v(\pi) \mathrm{N}^{+}$structure with a reverse bias voltage. Figure 1 shows the architecture of a reverse biased $\mathrm{P}^{+} \pi \mathrm{N}^{+}$heterostructure with two optional barriers at the ends of the absorber. The use of $\mathrm{N}^{+}$and $\mathrm{P}^{+}$areas with a wider band gap decreases the rate of thermal G-R processes; however, the lattice mismatch between the absorber and those areas generates misfit dislocations. An interesting case is the extension of the energy gap at the absorber's ends, which leads to the lowering of the rates of $\mathrm{G}-\mathrm{R}$ processes and introduces barriers to the flow of majority carriers 


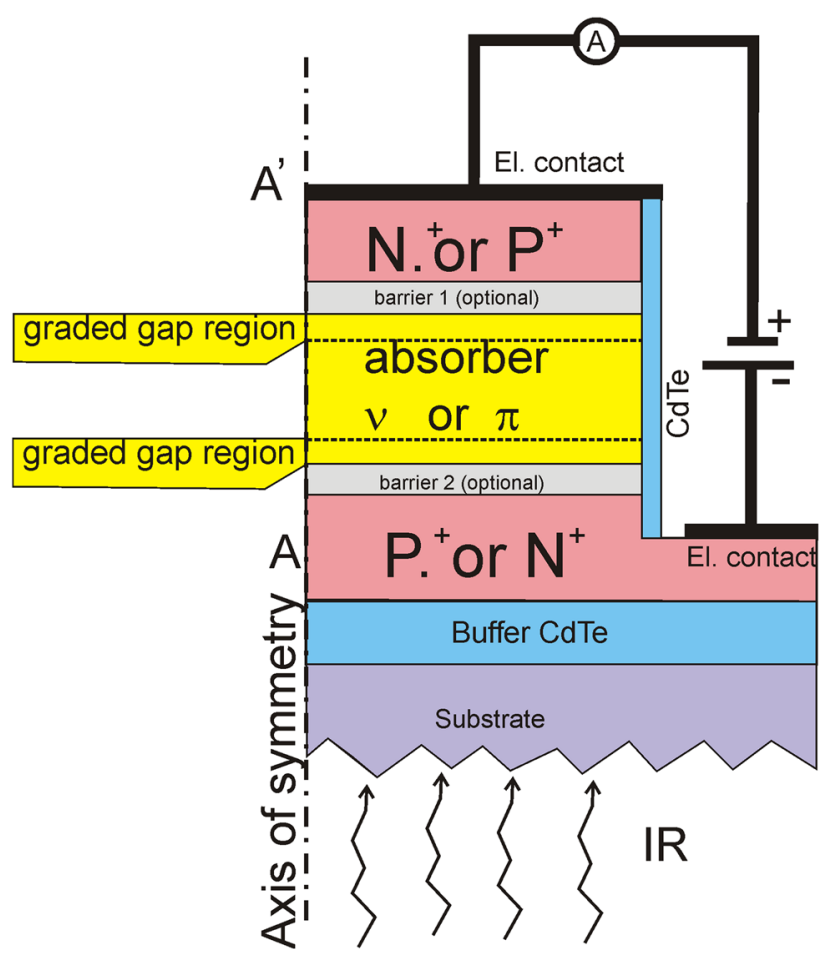

Fig. 1. The architecture of the half cross-section of cylindrical $\mathrm{P}^{+} v \mathrm{~N}^{+}$ LWIR mesa structure (with two optional barriers). The line-AA' indicates the direction of calculated spatial distributions of different parameters. The upper surface of a mesa is $1000 \mu \mathrm{m}^{2}$.

from electrical contacts. Dislocations constitute an additional channel for Shockley-Hall-Read (SHR) processes, ${ }^{15}$ which increases thermal generation despite the suppression of Auger processes in the absorber area. This phenomenon is analyzed in this work. We additionally consider the impact of the built-in electric field on the kinetics of SHR processes (trap assisted tunneling and Frankel-Pole effects) and band to band tunneling (BTBT). In this article we consider the influence of various G-R mechanisms on the parameters of the designed photodiodes, including the photon reabsorption (PR) effect, which significantly reduces the radiative $(R)$ recombination process. ${ }^{16}$ We investigate the optimal molar composition and doping in the barrier area, $\mathrm{N}^{+}$and $\mathrm{P}^{+}$areas to achieve the maximum possible absorber depletion effect of charge carriers at the lowest possible biased voltage. The photodiodes are designed for the detection of radiation with a wavelength of $10.6 \mu \mathrm{m}$ and for working at $230 \mathrm{~K}$ and $300 \mathrm{~K}$. The parameters of photodiodes (without barriers, with two barriers, and with different absorbers of type $\pi$ and type $v$ ) are calculated to find optimal structures. In this article, we designed barriers so that they do not hinder the effect of exclusion and extraction of carriers from the absorber area.

In addition to designing non-equilibrium HOT detectors, the aim of this work is to examine the contribution of individual G-R mechanisms in thermal generation and recombination and the impact of dislocations on these processes. Although the work does not contain experimental data, our programs have been experimentally verified many times in many previous works on $\mathrm{HgCdTe}$ heterostructures (for example in Refs. 17 and 18).

\section{NUMERICAL METHOD}

To solve the problem of carrier transport and photon reabsorption phenomena, we have added additional equations to the standard set of carrier transport equations. These equations, called the transport equations for photons, were presented in some of our previous works. ${ }^{16,19}$ The cited papers contain a detailed description of these equations. Transport equations for photons are related to the carrier transport equations through the inter-band radiative $\mathrm{G}-\mathrm{R}$ mechanism and by the equation of the energy balance. The equation of the energy balance (Eq. 4) has been thoroughly modified and extended to include the participation of photons. The set of transport equations, including the interaction of carriers with photon field, reads:

$$
\frac{\partial n}{\partial t}=\frac{1}{e} \nabla j_{n}+(\mathrm{G}-\mathrm{R})_{\mathrm{NR}}-\sum_{i=1}^{2} q_{0}^{i} \frac{\alpha^{i}}{\eta_{i}} c \frac{n p}{n_{0} p_{0}}+\sum_{i=1}^{2} q^{i} \frac{\alpha^{i}}{\eta_{i}} c
$$

$$
\frac{\partial p}{\partial t}=-\frac{1}{e} \nabla j_{p}+(\mathrm{G}-\mathrm{R})_{\mathrm{NR}}-\sum_{i=1}^{2} q_{0}^{i} \frac{\alpha^{i}}{\eta_{i}} c \frac{n p}{n_{0} p_{0}}+\sum_{i=1}^{2} q^{i} \frac{\alpha^{i}}{\eta_{i}} c
$$

$$
\nabla^{2} \Psi=-\frac{e}{\varepsilon \varepsilon_{0}}\left(N_{\mathrm{D}}^{+}-N_{\mathrm{A}}^{-}+p-n\right)-\frac{1}{\varepsilon} \nabla \Psi \nabla \varepsilon
$$

$$
\begin{aligned}
\frac{\partial u}{\partial t}= & C_{V} \frac{\partial T}{\partial t}=-\nabla(\zeta \nabla T)-\nabla\left(T \rho_{s_{p}} \mu_{p} \nabla \Phi_{p}\right) \\
& -\nabla\left(T \rho_{s_{n}} \mu_{n} \nabla \Phi_{n}\right)-\nabla\left(\Phi_{n} j_{e}\right)+\nabla\left(\Phi_{p} j_{p}\right) \\
& +\left(q_{0}^{1} \frac{\alpha^{1}}{\eta_{1}} c \frac{n p}{n_{0} p_{0}}-q^{1} \alpha^{1} \frac{c}{\eta_{1}}\right) \bar{E}_{q_{1}} \\
& +\left(q_{0}^{2} \frac{\alpha^{2}}{\eta_{2}} c \frac{n p}{n_{0} p_{0}}-q^{2} \alpha^{2} \frac{c}{\eta_{2}}\right) \bar{E}_{q_{2}}
\end{aligned}
$$

$$
\frac{\partial q^{1}}{\partial t}=q_{0}^{1} \frac{\alpha^{1}}{\eta_{1}} c \frac{n p}{n_{0} p_{0}}-q^{1} \alpha^{1} \frac{c}{\eta_{1}}-\nabla j_{q^{1}}
$$

$$
\frac{\partial q^{2}}{\partial t}=q_{0}^{2} \frac{\alpha^{2}}{\eta_{2}} c \frac{n p}{n_{0} p_{0}}-q^{2} \alpha^{2} \frac{c}{\eta_{2}}-\nabla j_{q^{2}}
$$

where the current density of $i$-kind photons reads $j_{q^{i}}=q_{i} c / 4 \eta_{i}^{3}$, index $p$ refers to holes and index $n$ to electrons, respectively, $n$ denotes electron concentration, $p$ hole concentration, index 0 refers to thermal equilibrium, $c$ is the speed of light, $\eta$ the 
refractive index, $\quad \nabla$ the gradient, $\bar{E}_{q_{i}}=$ $\frac{1}{q_{0}^{i}} \int_{E^{i}}^{E^{i}}+\Delta E^{i} \frac{\partial q_{0}(v)}{\mathrm{d} v} h v \mathrm{~d} v$ is the average energy of photons from the energy range $\Delta E^{i}, \frac{\partial q_{0}(v)}{d v}$ is the Planck distribution function, density of photons $q_{0}^{i}=\int_{E^{i}}^{E^{i}+\Delta E^{i}} \frac{\partial q_{0}(v)}{d v} \mathrm{~d} v, e$ is the elementary charge, $C_{V}$ specific heat, and $\zeta$ is the coefficient of thermal conductivity. $(\mathrm{G}-\mathrm{R})_{\mathrm{NR}}$ is the total net non-radiative generation rate determined by Auger 1, Auger 7 and SHR processes, $\rho_{\mathrm{s}}$ denotes the density of entropy, $\mu$ is the mobility and $j$ is the current density. Solving the set of transport Eqs. 1-6 by using the iterative methods, we obtain a spatial distribution of quasi Fermi energies $\Phi_{n}$ and $\Phi_{p}$, electric potential $\Psi$, temperature $T$ and density of photons $q_{1}$ and $q_{2}$. Using these data, we can determine all physical quantities occurring in the transport process in the heterostructure. Here we have distinguished two types of averages, $\bar{E}_{q_{i}}$ in energy ranges $E_{\mathrm{G}}($ abs. $) \leq$ $E_{q_{1}}<E_{\mathrm{G}}\left(\mathrm{N}^{+}, \mathrm{P}^{+}\right)$and $E_{q_{2}} \geq E_{\mathrm{G}}\left(\mathrm{N}^{+}, \mathrm{P}^{+}\right)$, however the number of averages may be increased depending on one's needs. $E_{\mathrm{G}}$ is the energy gap, and index abs denotes the absorber. $\mathrm{N}^{+}, \mathrm{P}^{+}$are regions presented in Fig. 1. $\alpha^{i}$ is the average absorption coefficient for photons associated in the specified energy range. Sample results of calculations as a function of thickness along the axis of symmetry of a mesa structure are shown in the figures below. The upper surface of a mesa is $1000 \mu \mathrm{m}^{2}$. The CdTe mole fraction $\mathrm{x}$ in the absorber is selected so that the cut off wavelength $\lambda_{\text {co }}=1.24 / E_{\mathrm{G}}(\mathrm{in} \mathrm{eV})$ is equal $12 \mu \mathrm{m}$.

\section{RESULTS OF CALCULATIONS}

We have analyzed the LWIR $\mathrm{P}^{+} v \mathrm{~N}^{+}$cylindrical mesa structures working at $230 \mathrm{~K}$ and $300 \mathrm{~K}$. The architecture of the half cross-section of these structures (with two optional barriers) is shown in Fig. 1.

We marked barrierless structures as $\mathrm{A}$, and the structures with two barriers as C. The detector working at $230 \mathrm{~K}$ has an absorber with a thickness of about $5 \mu \mathrm{m}$, and in $300 \mathrm{~K}$ a thickness of $2.5 \mu \mathrm{m}$. Figure 2 presents assumed spatial distribution of mole fraction $x$, donor concentration $N_{\mathrm{D}}$, acceptor concentration $\mathrm{N}_{\mathrm{A}}$ and concentrations of metal vacancies $N_{\mathrm{T}}$ in structures $\mathrm{C}$ working at $300 \mathrm{~K}$ (Fig. 2a) and $230 \mathrm{~K}$ (Fig. 2b). $N_{\mathrm{T}}$, the concentration of metal vacancies, is a technical variable which strongly depends on annealing conditions. Experimental determination is possible only by indirect methods, for example by measuring the lifetime of carriers. The absorber in $300 \mathrm{~K}$ should be thinner than that in $230 \mathrm{~K}$. The effect of exclusion and extraction of carriers in a thinner absorber covers the entire area, whereas with a thicker absorber the effect occurs only in part. The condition for suppressing the Auger generation is to reduce the carrier concentration. Both $\mathrm{C}$ structures have identical molar composition and dopant concentrations and thicknesses of the $\mathrm{N}^{+}$and $\mathrm{P}^{+}$regions surrounding the absorber. They differ only in $\mathrm{x}$, the mole fraction of CdTe, and thickness of the absorber area. At the boundaries of the absorber there are thin layers with an expanded energy gap that act as energy barriers for holes and electrons. These layers must be strongly doped to fulfill their role; the same applies to the $\mathrm{N}^{+}$and $\mathrm{P}^{+}$areas surrounding the absorber. The absorber area is type $v$ with a concentration of donors $N_{\mathrm{D}}=2 \cdot 10^{14} \mathrm{~cm}^{-3}$ and has a resistivity much higher than the resistivity of the surrounding areas. The A structure is a simpler technological solution, which does not have energy barriers at the absorber's boundary. The use of these barriers, however, improves the parameters of the detectors, which will be presented in the following figures. The simulations carried out by us indicate that for such improvement to take place, these barriers should be placed on the absorber's boundary. We also analyzed structures with a $\pi$ type absorber with a concentration of acceptors $N_{\mathrm{A}}=2$ $\cdot 10^{14} \mathrm{~cm}^{-3}$, obtaining very similar results as in the case of an $v$ type absorber (current-voltage characteristic $j(\mathrm{~V})$ and quantum efficiency $\eta$ ). In our work, we focus only on structures with $v$ type absorber. In
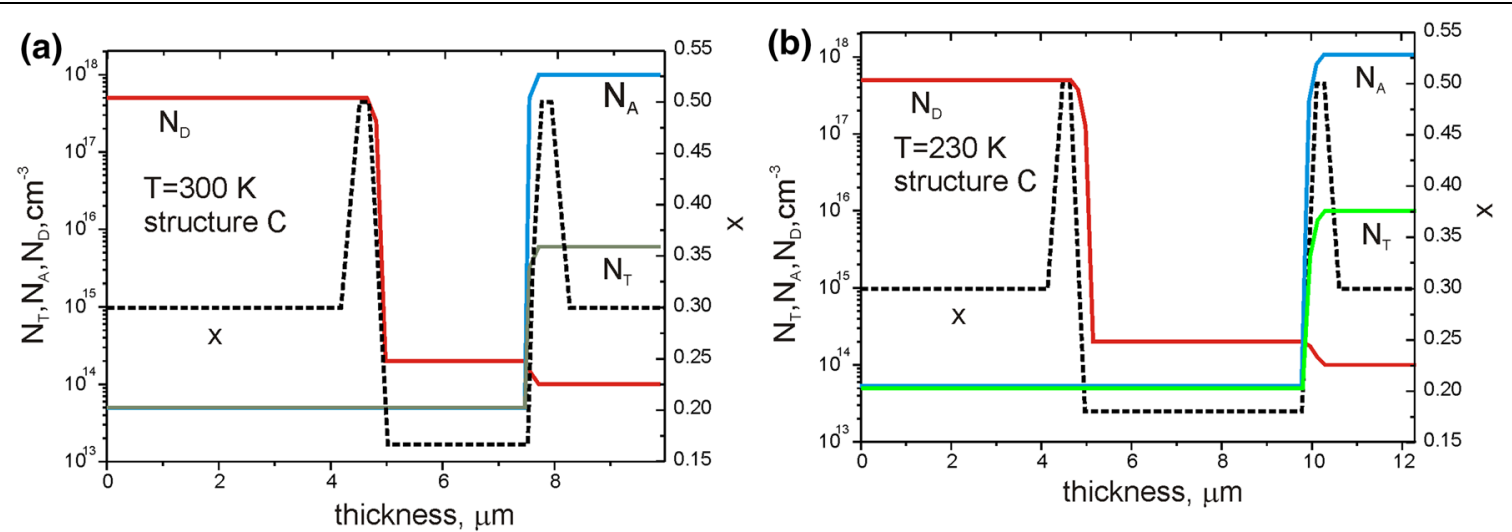

Fig. 2. Spatial distribution of mole fraction $x$, donor concentration $N_{\mathrm{D}}$, acceptor concentration $N_{\mathrm{A}}$ and concentrations of metal vacancies $N_{\mathrm{T}}$ in structures $\mathrm{C}$ at $300 \mathrm{~K}(\mathrm{a})$ and at $230 \mathrm{~K}$ (b). Structures A differ from the structures $\mathrm{C}$ by the lack of barriers at the absorber boundaries. 
a forthcoming work, we intend to simulate current noise and the response speed of structures with $v$ and $\pi$ type absorbers to ultimately determine which solution is better.

Figure 3 show the distribution of energy band edges in four photodiodes analyzed after biasing with reverse voltage $-0.4 \mathrm{~V}$ (continuous lines), and low voltage $-0.02 \mathrm{~V}$ or $-0.04 \mathrm{~V}$ (dashed lines). Structures $\mathrm{C}$ are practically free of band off-set. In both structures $\mathrm{A}$ and $\mathrm{C}$, the applied voltage is deposited in the absorber area. After biasing with $-0.4 \mathrm{~V}$ voltage there are conditions for BTBT. BTBT generation rate in structures $\mathrm{C}$ is lower than in A, especially in $T=300 \mathrm{~K}$, due to the smaller overlap of the $E_{\mathrm{C}}$ and $E_{\mathrm{V}}$ band. Figure 4 show the spatial distribution of the electric field intensity under conditions of weak and strong biasing in the reverse direction. Accompanied by the increase in polarization voltage, the increase in the electric field intensity occurs practically only in the absorber. This is a very beneficial phenomenon that causes the extraction and exclusion of electrical charge carriers from the absorber area.

Figure 5 shows that in both structures $\mathrm{A}$ and $\mathrm{C}$ the largest concentrations of charge carriers occur in the area at the border with the $\mathrm{N}^{+}$layer. Exclusion of carriers from this area (especially at
$300 \mathrm{~K})$ is much more effective in $\mathrm{C}$ structures. Extraction occurring at the border with the $\mathrm{P}^{+}$area is more effective in structures A than in C. Therefore, the concentration of carriers at the $\mathrm{P}^{+}$boundary is smaller in structures A than in C.

The rate of recombination is more strongly dependent on the concentration of charge carriers than on the recombination rate. Figure 6 shows spatial distribution of thermal generation rate caused by different $\mathrm{G}-\mathrm{R}$ processes at $230 \mathrm{~K}$ in structure A (Fig. 6a) and in structure $\mathrm{C}$ (Fig. 6b). Figure 7 show the recombination rate in these structures. Reverse bias voltage that causes the exclusion and extraction of charge carriers is the reason for suppression of thermal generation determined by the mechanisms A1, A7 and R (solid lines). In the case of SRH generation, the polarization rate increases slightly. Spectacular reduction of $\mathrm{A} 1$ and $\mathrm{A} 7$ generation because of carrier extraction is observed in the absorber's area on the border with the $\mathrm{P}^{+}$layer. The extraction effect in structure $\mathrm{A}$ is stronger than in C. Near the border with the $\mathrm{N}^{+}$layer in the structure $\mathrm{C}$ we have a reduction in generation rate of the A1 mechanism by an order of magnitude after polarization with $-0.4 \mathrm{~V}$. Suppression of generation in this area is approximately twice lower in the structure A. Similar results can be observed for
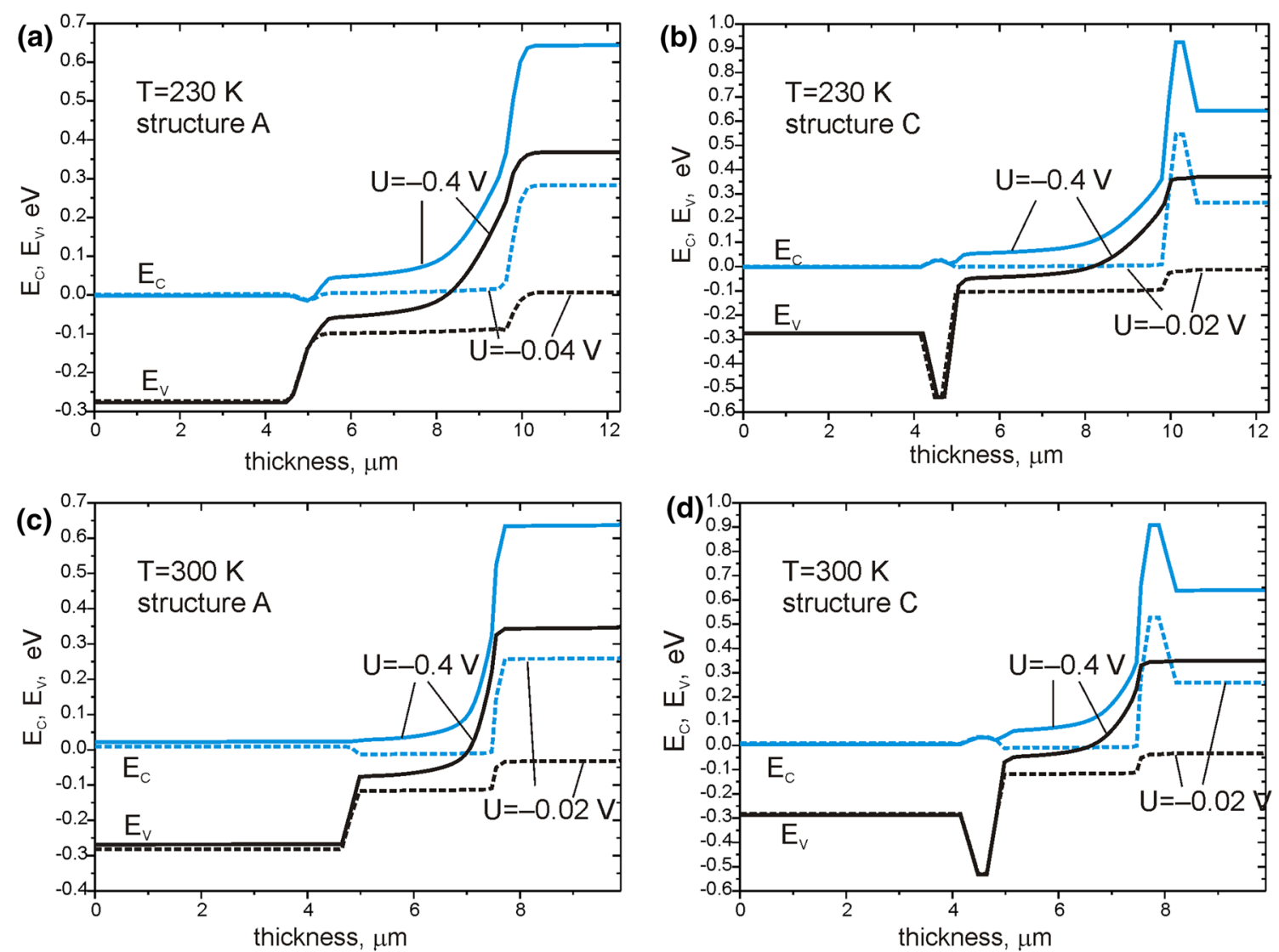

Fig. 3. Spatial distribution of the band structure with an arbitrarily chosen bias voltage at $230 \mathrm{~K}(\mathrm{a}, \mathrm{b})$ and at $300 \mathrm{~K}(\mathrm{c}, \mathrm{d})$ in structure $\mathrm{A}(\mathrm{a}, \mathrm{c})$ and $\mathrm{C}$ (b, d). Band to band tunneling is possible for $\mathrm{A}$ and $\mathrm{C}$ structures working at $300 \mathrm{~K}$ after biasing with $-0.4 \mathrm{~V}$ voltage. 

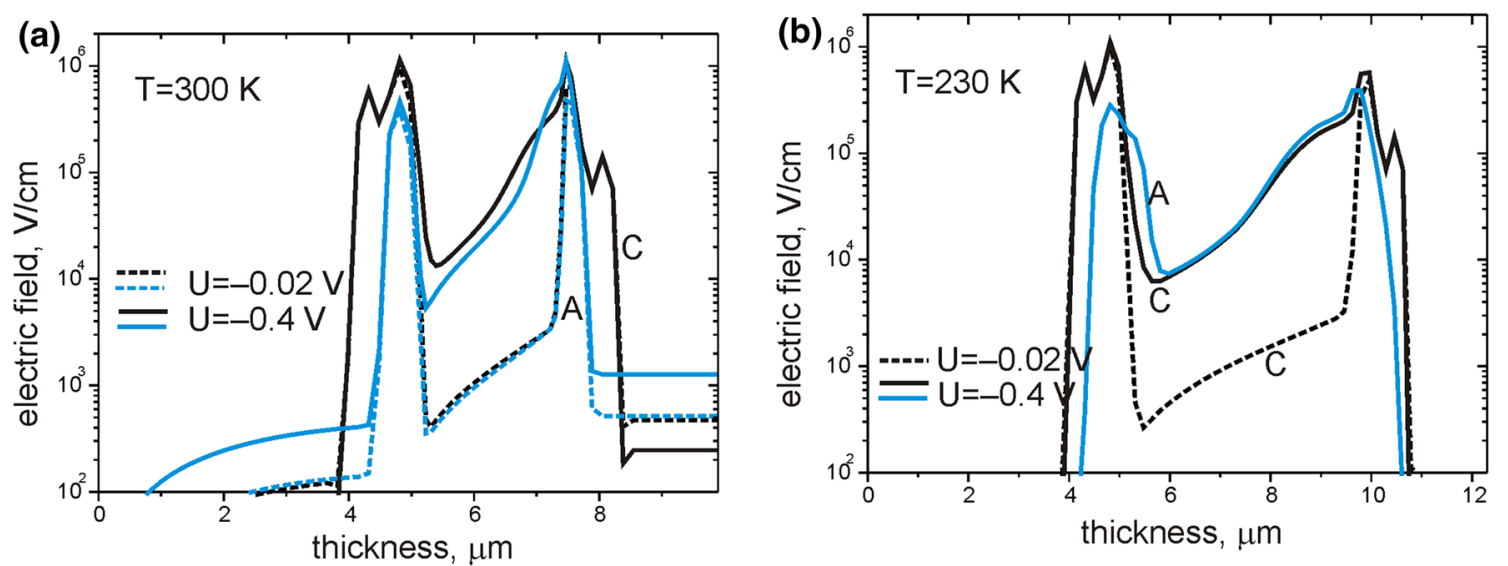

Fig. 4. Distribution of the electric field in structures $\mathrm{A}$ and $\mathrm{C}$ at the polarization voltage $-0.02 \mathrm{~V}$ (dashed lines) and $-0.4 \mathrm{~V}$ solid lines at $300 \mathrm{~K}$ (a) and $230 \mathrm{~K}$ (b). Increasing the bias voltage causes a significant increase in the intensity of the electric field in the absorber.
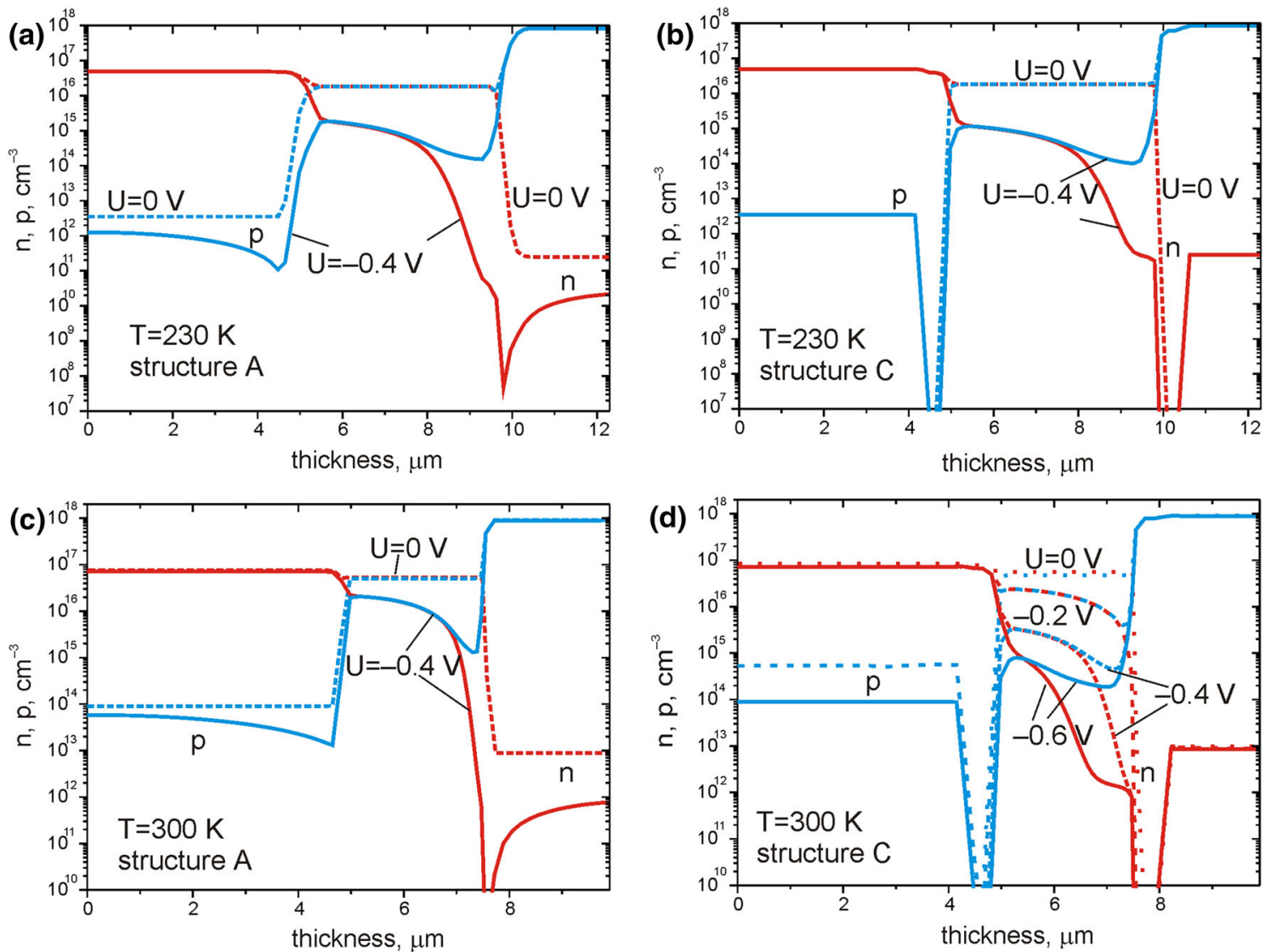

Fig. 5. (a-d) Spatial distribution of electron concentration $n$ and hole concentration $p$ in the analyzed structures in thermal equilibrium and after polarization with the voltage marked with the curves. Biasing in the reverse direction leads to strong decreases in electron and hole concentration. Particularly strong changes in electron concentration are caused by the effect of exclusion at the absorber boundary with the $\mathrm{P}^{+}$ area.

recombination rates. Polarization in the reverse direction suppresses recombination much more strongly than generation. The rate of recombination is more strongly dependent on the concentration of carriers than the generation rate. ${ }^{6-20}$ Similar conclusions can be made by analyzing Figs. 8 and 9 for structures $\mathrm{A}$ and $\mathrm{C}$ working at $300 \mathrm{~K}$.
Decreasing the concentration of carriers in the absorber area leads to an increase in the resistivity of the structures and thus affects the characteristics of $j(\mathrm{~V})$ and dynamic resistance of photodiodes. This is shown in Fig. 10. At $230 \mathrm{~K}$ (Fig. 10a) characteristics of $j(\mathrm{~V})$ in structures $\mathrm{A}$ and $\mathrm{C}$ are very similar, but for larger bias voltages one can observe 
Enhanced Numerical Modeling of HgCdTe Long Wavelength Infrared Radiation High Operating Temperature Non-equilibrium $\mathrm{P}^{+} v(\pi) \mathrm{N}^{+}$Photodiodes
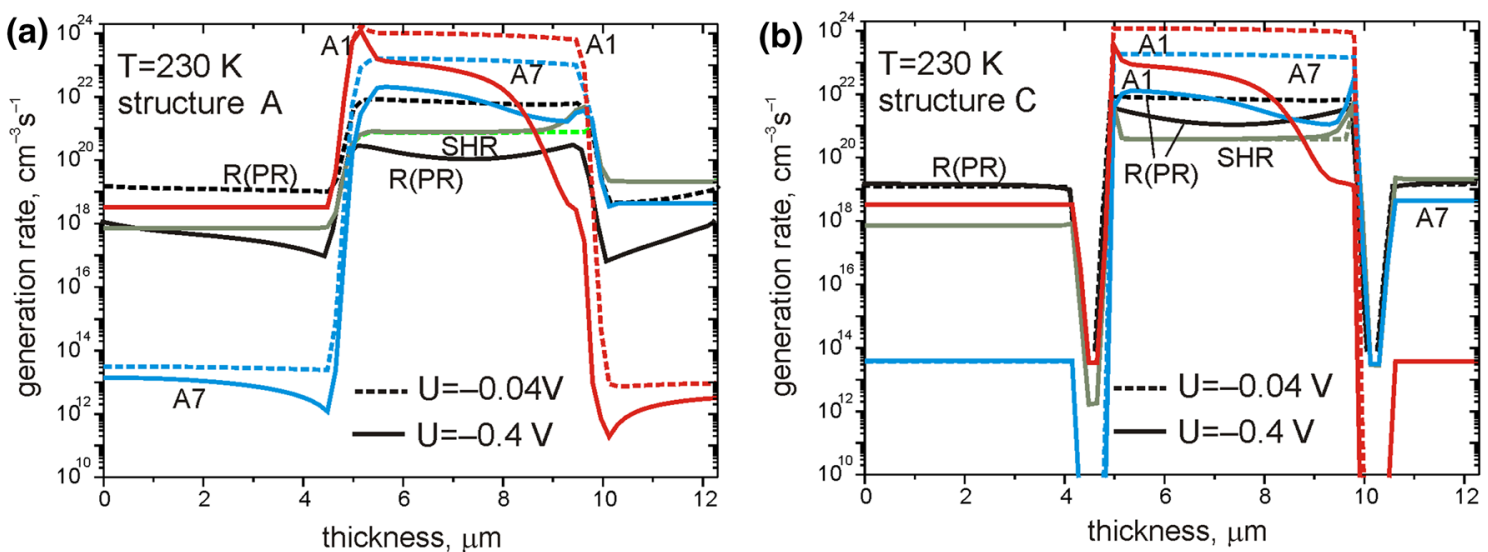

Fig. 6. Distribution of generation rate caused by the mechanism A1, A7, SHR caused by mercury vacancies and dislocations, radiative $(R)$ generation including the phenomenon of photon reabsorption at $230 \mathrm{~K}$ in the structure $\mathrm{A}(\mathrm{a})$ and $\mathrm{C}$ (b). Decreases of electron and hole concentration shown in Fig. 5 reduce the generation rate for all mechanisms except SHR mechanisms.
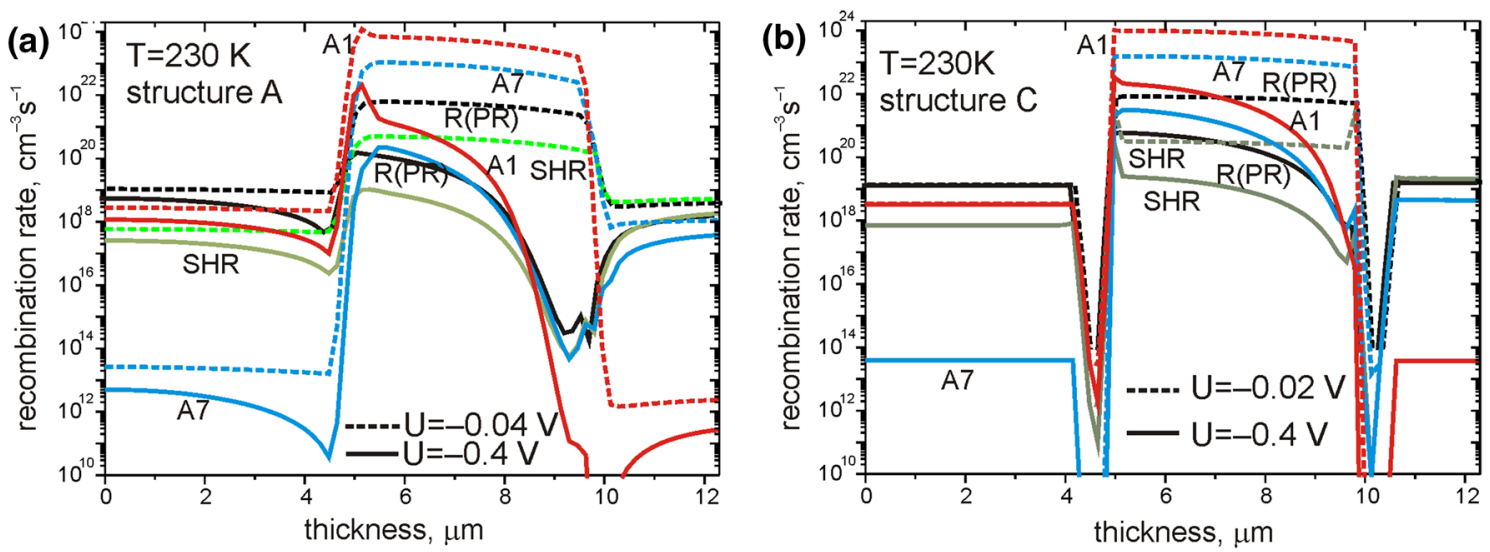

Fig. 7. Distribution of recombination rate determined by various $\mathrm{G}-\mathrm{R}$ mechanisms at $230 \mathrm{~K}$ in structures $\mathrm{A}$ (a) and $\mathrm{C}$ (b). The suppression of the recombination rate is much stronger than the suppression of the generation shown in Fig. 6.
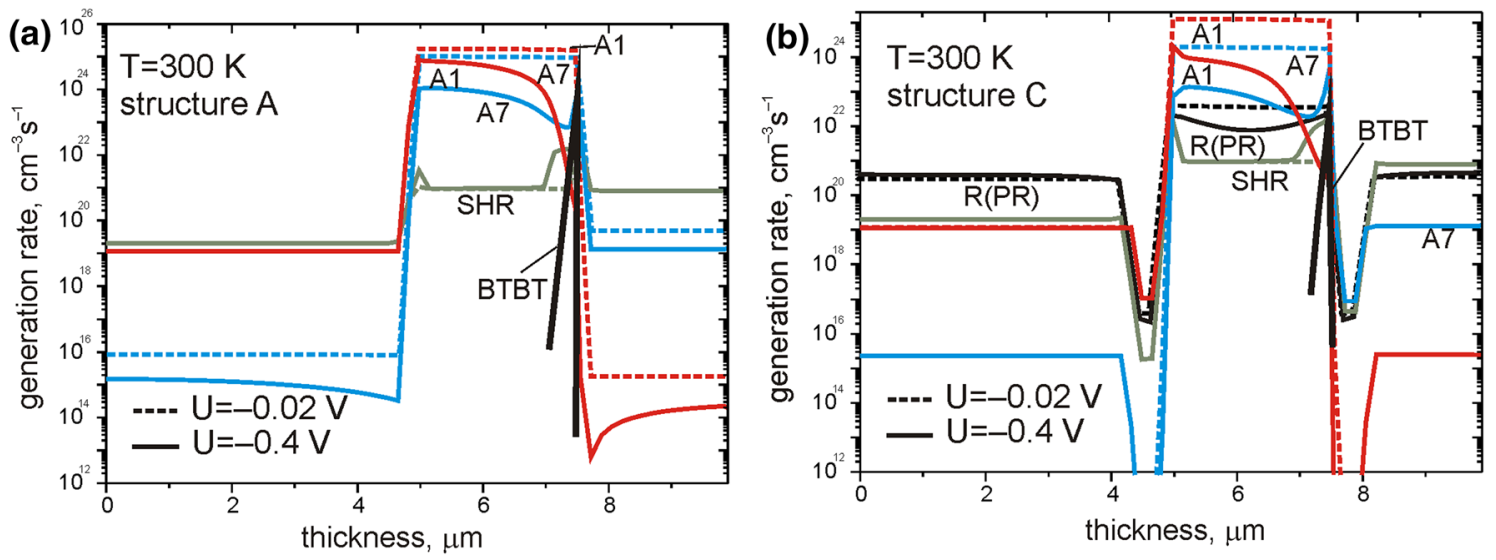

Fig. 8. Distribution of generation rate determined by various $\mathrm{G}-\mathrm{R}$ mechanisms at $T=300 \mathrm{~K}$ in structure A (a) and structure C (b). BTBT stands for the generation rate caused by band to band tunneling.

approximately twice lower current density in $\mathrm{C}$, and thus a greater dynamic resistivity. Negative values of dynamic resistance in the voltage range from $-0.75 \mathrm{~V}$ to $-0.1 \mathrm{~V}$ are shown in the Fig. 9a. The current density in the $\mathrm{C}$ structure at $-0.4 \mathrm{~V}$ is about $3 \mathrm{~A} / \mathrm{cm}^{2}$. We observe much larger dark currents for structures at $300 \mathrm{~K}$ (Fig. 10b). The lines in red refer to structure $\mathrm{C}$ having an absorber 

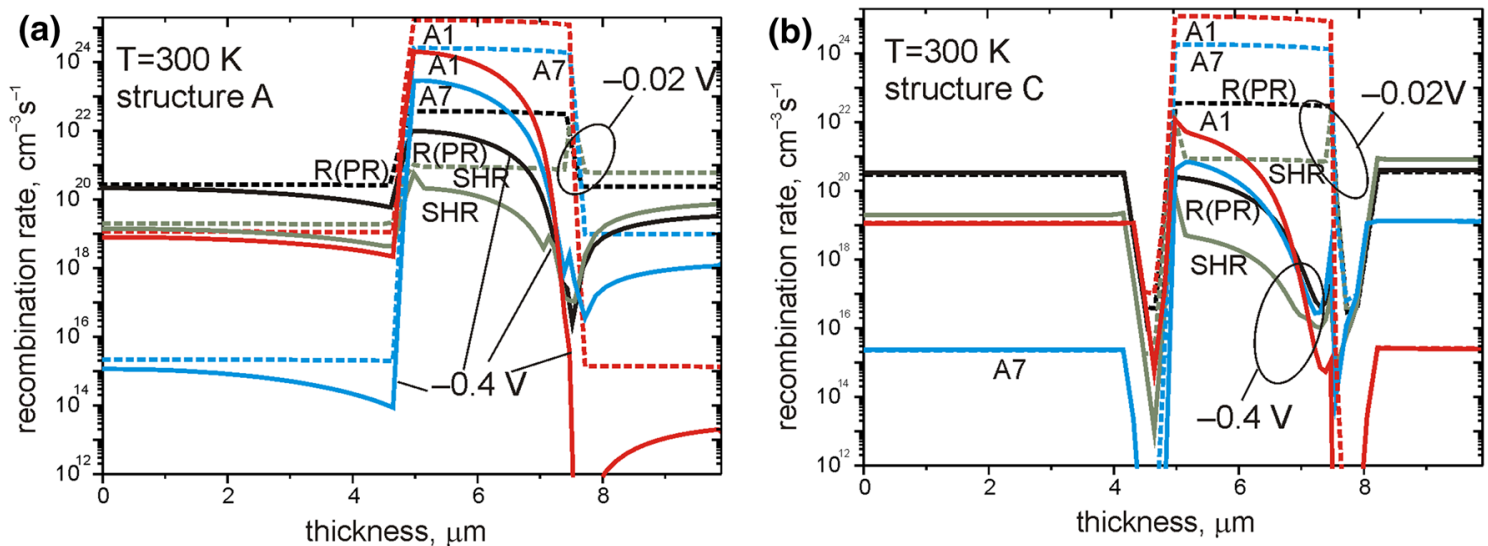

Fig. 9. Distribution of recombination rate determined by various $\mathrm{G}-\mathrm{R}$ mechanisms at $T=300 \mathrm{~K}$ in structure $\mathrm{A}(\mathrm{a})$ and structure $\mathrm{C}$ (b).
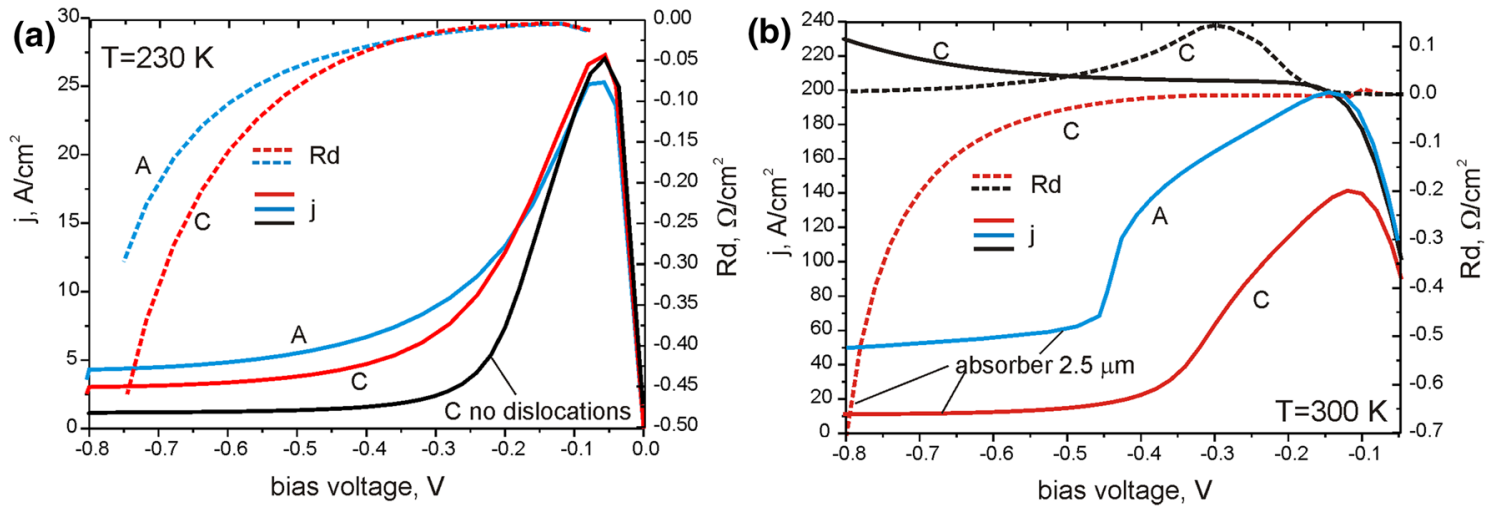

Fig. 10. Normalized current-voltage characteristics (in $\mathrm{A} / \mathrm{cm}^{2}$ )—continuous lines and normalized dynamic resistance (in $\Omega / \mathrm{cm}^{2}$ )—dashed lines as a function of the reverse bias voltage for structures $A$ and $C$ operating at $230 \mathrm{~K}(\mathrm{a})$ and $300 \mathrm{~K}(\mathrm{~b})$.
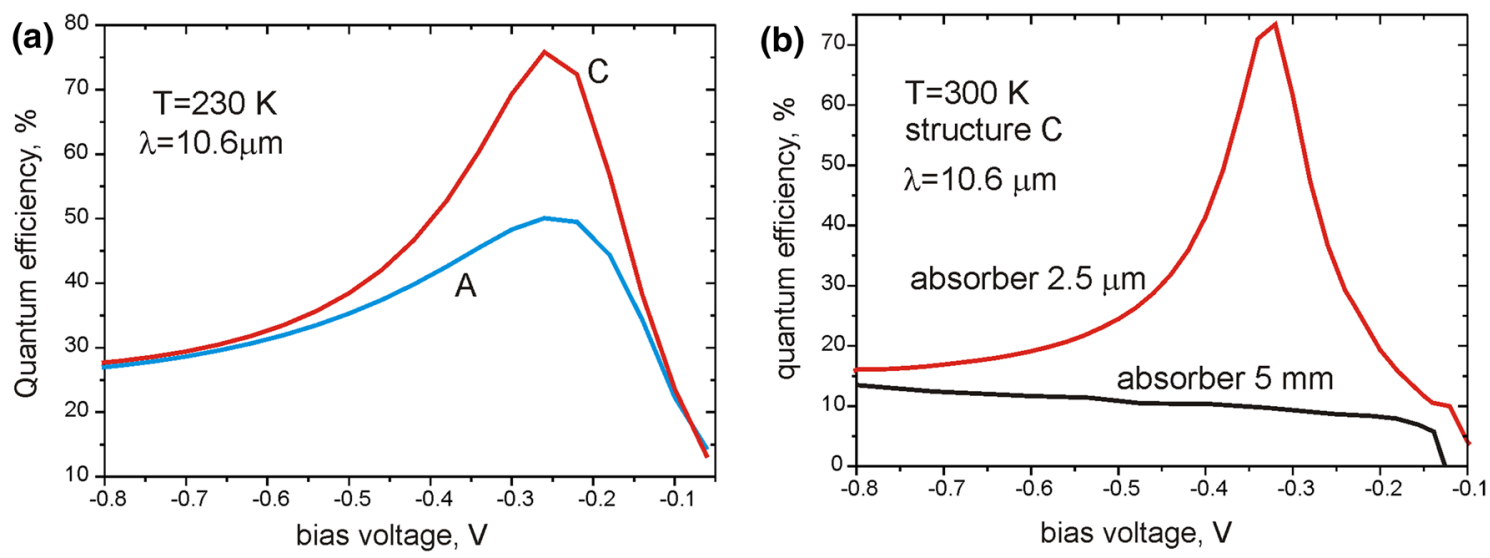

Fig. 11. Quantum efficiency for radiation with $10.6 \mu \mathrm{m}$ wavelength in structure $\mathrm{A}$ and $\mathrm{C}$ at $230 \mathrm{~K}(\mathrm{a})$ and at $300 \mathrm{~K}$ in structures $\mathrm{C}$ with absorber of thicknesses $2.5 \mu \mathrm{m}$ and $5 \mu \mathrm{m}$ (b).

with a thickness of $5 \mu \mathrm{m}$, which is too large for the phenomenon of exclusion and extraction to effectively reduce the concentration of the carriers in it.
The current density after polarity with blocking voltage above $0.1 \mathrm{~V}$ is above $200 \mathrm{~A} / \mathrm{cm}^{2}$ and the dynamic resistance has positive values. Decreasing the absorber thickness to $2.5 \mu \mathrm{m}$ radically changes 
the shape of the $j(\mathrm{~V})$ curve. In structure $\mathrm{C}$ for voltage $-0.4 \mathrm{~V}$, the current density is around $20 \mathrm{~A} /$ $\mathrm{cm}^{2}$; in structure A it is more than five times greater.

Figure 11 shows the dependence of quantum efficiency for radiation with a wavelength $\lambda=10.6 \mu \mathrm{m}$ from the bias voltage. At $230 \mathrm{~K}$, quantum efficiency in $\mathrm{C}$ and A structures has a similar course. First it grows, with the voltage reaching its maximum around $-0.25 \mathrm{~V}$. For this voltage, we observe minimal values of dynamic resistance. An increase in resistance with increasing supply voltage reduces the quantum efficiency of photodiodes working in short-circuit conditions as a current source. In both structures there is a photo-current gain ${ }^{21}$ despite a weak absorption coefficient of about $1000 \mathrm{~cm}^{-1}$ in the absorber area, the quantum efficiency in the $\mathrm{C}$ structure reaches over $70 \%$. The absorption coefficient calculation is based on Andersson's work. ${ }^{22}$ We have also considered absorption in the Urbach's tails using the Finkman and Nemirovsky model. ${ }^{23}$ At $300 \mathrm{~K}$ photo-current gain in the structure of absorber C, a thickness of $2.5 \mu \mathrm{m}$ causes the effective quantum efficiency has a maximum of over $70 \%$. In the $\mathrm{C}$ structure with a $5 \mu \mathrm{m}$ thick absorber, quantum efficiency is only around $10 \%$. When calculating quantum efficiency, we consider the total reflection of radiation from the upper contact. Continuous lines refer to bias voltage $U=-0.4 \mathrm{~V}$, dashed lines to $U=-0.04 \mathrm{~V}$. Dotted lines represent the density of dislocations. The black line refers to structure $\mathrm{C}$ without dislocations.

Figure 12 shows the dependence of quantum efficiency on wavelength in structures $A$ (dashed lines), and $\mathrm{C}$ (solid lines) in the $6-11 \mu \mathrm{m}$ range. The curves were obtained for different bias voltages (marked on curves). The thickness of the absorber in both structures is $5.5 \mu \mathrm{m}$. An increase of the bias voltage in the reverse direction results in an increase in quantum efficiency. For $-0.4 \mathrm{~V}$ voltage, it exceeds $100 \%$ for radiation with a wavelength less than $8 \mu \mathrm{m}$. This is the result of the existing photoelectric gain, which depends both on the

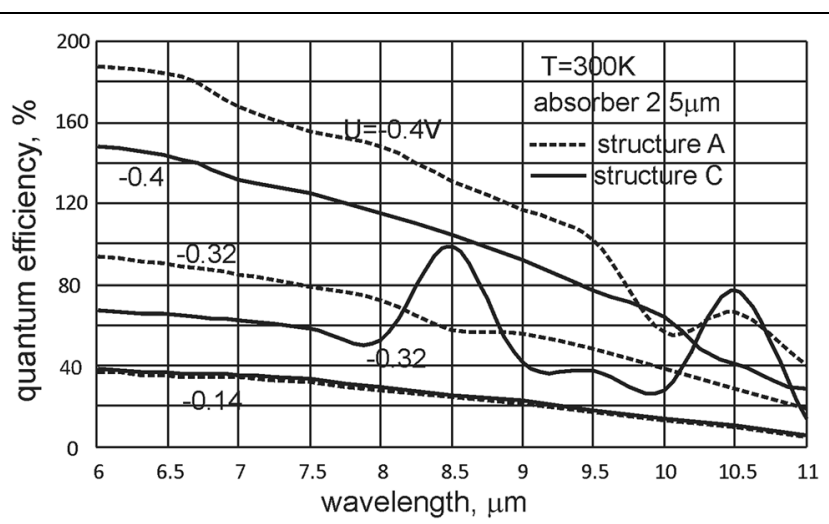

Fig. 12. The dependence of quantum efficiency on wavelength for structure A (dashed lines) and C (solid lines) at $300 \mathrm{~K}$. The numbers on the curves indicate the values of the bias voltage. voltage applied and on the place of the carrier generation by photons. ${ }^{21}$ In the $\mathrm{C}$ structure for voltages near $-0.3 \mathrm{~V}$, we observe the oscillating nature of spectral characteristics of quantum efficiency.

Figure 13 presents value of the absorption coefficient $\alpha$ of radiation of wavelength $\lambda=10.6 \mu \mathrm{m}$ in the absorber in structure C. Reduction of the carrier concentration in reverse bias reduces the Burstein Moss effect, which helps to increase the absorption coefficient. We observe about a two-fold increase in $\alpha$ when biasing the structures with $-0.4 \mathrm{~V}$ voltage. Further increase in voltage slightly affects the growth of $\alpha$. Figure 14 shows the total net thermal generation rate considering the impact of dislocations. We assumed dislocation density in the structure equal to $10^{6} \mathrm{~cm}^{-2}$, which seems realistic. In the areas where the molar composition gradient occurs, the density of dislocations is calculated according to the dependence proposed by Yamamoto et al. ${ }^{24}$ and exceeds $10^{8} \mathrm{~cm}^{-2}$. If we do not consider the impact of dislocations, the net thermal generation rate is several times smaller. Counting the parameters of the presented diodes, we assumed the existence of dislocations with a distribution as in Fig. 14.

Figure 15 shows calculated noise currents at $\Delta f=1 \mathrm{~Hz}$ in structure $\mathrm{C}$ at $300 \mathrm{~K}$ as frequency functions. At this temperature G-R noise dominates. The increase of the bias voltage in the reverse direction reduces the generation and recombination rate, and the spectral density of this G-R noise, which is proportional to the sum of the generation and recombination rates. Noise currents are derived by numerically solving the system of transport equations for fluctuation. These equations and the appropriate procedures are described in our earlier works. ${ }^{25,26}$ Suppression of heat generation and recombination allows for a significant increase in the normalized detectivity $D^{*}$. Biasing structure $\mathrm{C}$ with the reverse voltage in the range $-0.3 \mathrm{~V}$ to $-0.2 \mathrm{~V}$, we can obtain $D^{*}$ greater than $10^{9} \mathrm{cmHZ}^{1 /}$ ${ }^{2} \mathrm{~W}^{-1}$.

\section{CONCLUSIONS}

Enhanced numerical analysis of photoelectric and fluctuating phenomena in heterostructures allows for the design of HOT detectors with high normalized detectivity $D^{*}$. By applying heterostructures in $\mathrm{P}^{+} v \mathrm{~N}^{+}$or $\mathrm{P}^{+} \pi \mathrm{N}^{+}$configurations to non-equilibrium LWIR photodiodes, we can obtain the values of $D^{*}$ that enable their technical application without the cryogenic cooling. The use of the two additional barriers at the absorber boundaries improves the detection parameters of non-equilibrium detectors. It enhances the effect of carrier exclusion and electro-optical gain. This is especially visible for detectors working in $300 \mathrm{~K}$. In this case, strong electro-optical gain allows achieving effective quantum efficiency of up to $70 \%$ despite the low values of the absorption coefficient and the small thickness of 

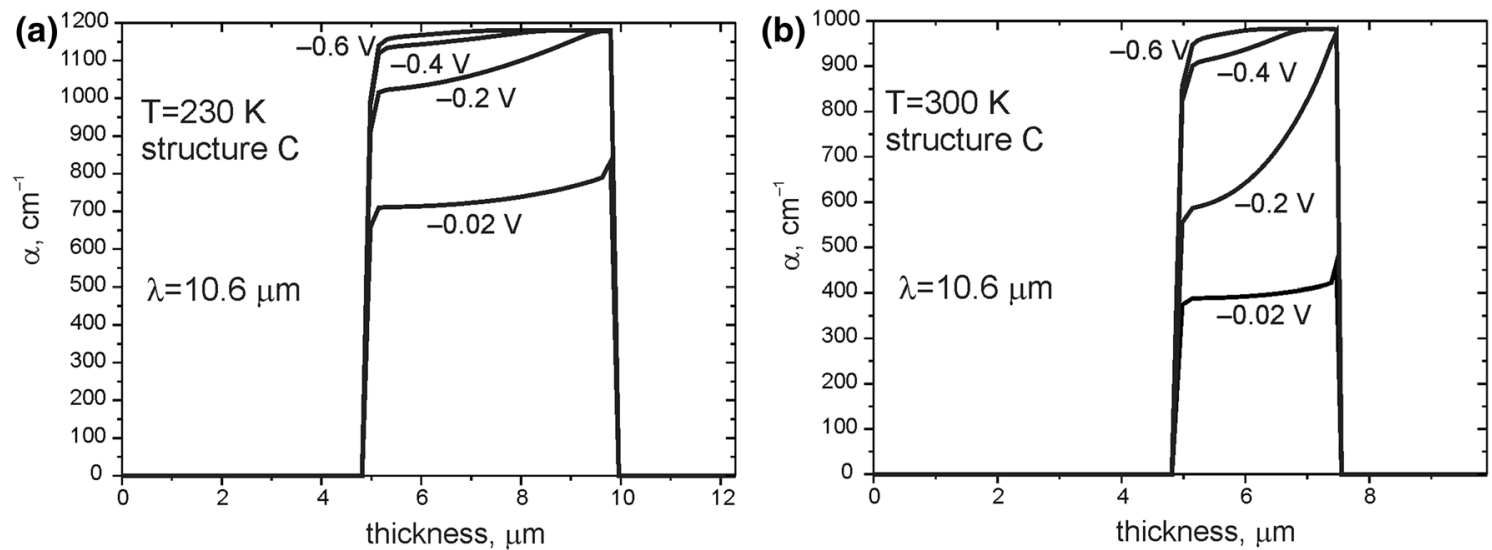

Fig. 13. Absorption coefficient for radiation with the wavelength $10.6 \mu \mathrm{m}$ in the structure $\mathrm{C}$ in $T=230 \mathrm{~K}(\mathrm{a})$ and $300 \mathrm{~K}(\mathrm{~b})$ for the selected values of the reverse voltage.

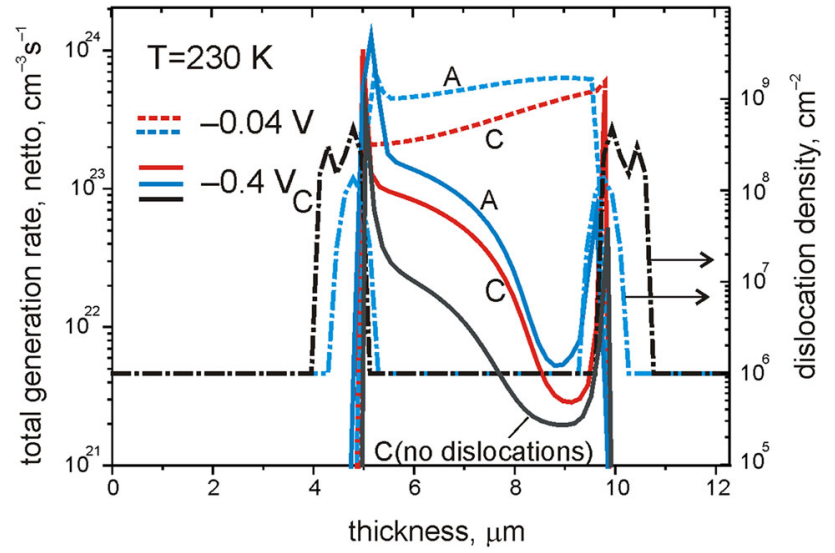

Fig. 14. Distribution of the total net generation rate in the structures of $\mathrm{A}$ and $\mathrm{C}$ in $T=230 \mathrm{~K}$ biased with $-0.4 \mathrm{~V}$ (solid lines) and with $-0.04 \mathrm{~V}$ (dashed lines). Dot-dashed lines denote the density of dislocations. The black continuous line refers to the $\mathrm{C}$ structure, where no dislocations occur.

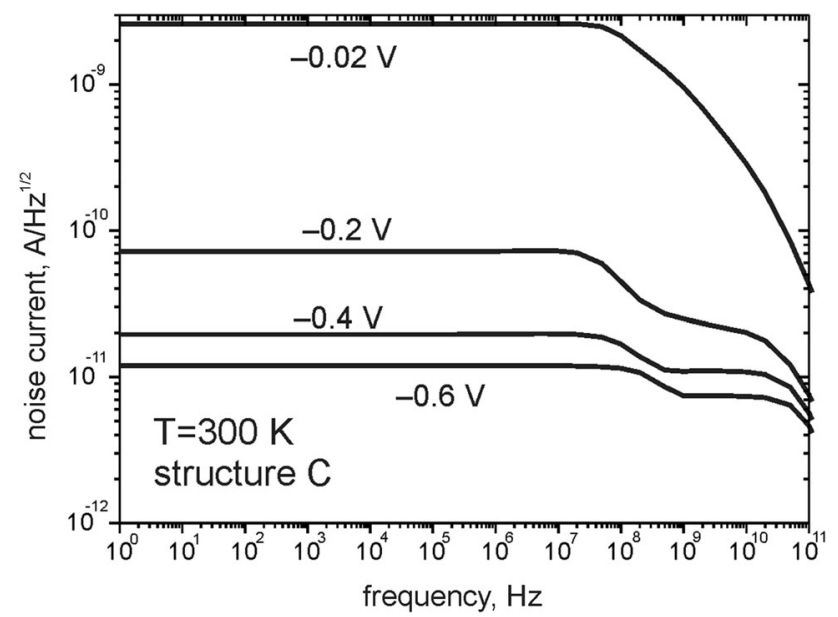

Fig. 15. Calculated noise current at $\Delta f=1 \mathrm{~Hz}$ as a function of frequency for structure $\mathrm{C}$ at $300 \mathrm{~K}$ for chosen bias voltage. the absorber. Calculation results indicate that the optimal range of polarizing voltages is in the range $-0.4 \mathrm{~V}$ to $-0.2 \mathrm{~V}$. Extraction and exclusion of carriers caused by these voltages effectively suppresses generation and thermal recombination, which allows around 100-fold reduction of G-R noise currents. The calculations show that the rate of generation and thermal recombination at temperatures close to $200 \mathrm{~K}$ is strongly influenced by dislocations. If these were to be eliminated, the $G-R$ thermal processes would be reduced several times. A much smaller impact of dislocations occurs at $300 \mathrm{~K}$. The calculated value of the $D^{*}$ for a twobarrier structure at $300 \mathrm{~K}$ exceeds the value of $10^{9} \mathrm{cmHZ}^{1 / 2} \mathrm{~W}^{-1}$. Further work will continue calculations aimed for optimization of the presented structures, including structures with a $\pi$ type absorber as well. We will also carry out the calculation of the response speed and present a map of the generation of current noise taking into account the share of individual types of noise sources.

\section{ACKNOWLEDGMENTS}

The work has been undertaken under the financial support of the Polish National Science Centre as research Project No DEC-2016/23/B/ST7/03958.

\section{OPEN ACCESS}

This article is distributed under the terms of the Creative Commons Attribution 4.0 International License (http://creativecommons.org/licenses/by/4.0/ ), which permits unrestricted use, distribution, and reproduction in any medium, provided you give appropriate credit to the original author(s) and the source, provide a link to the Creative Commons license, and indicate if changes were made. 1

\section{REFERENCES}

1. M.A. Kinch, F. Aqariden, D. Chandra, P.-K. Liao, H.F. Schaake, and H.D. Shih, J. Electron. Mater. 34, 880 (2005). 
2. P.Y. Emelie, J.D. Phillips, S. Velicu, and C.H. Grein, J. Electron. Mater. 36, 846 (2007).

3. A.M. Itsuno, J.D. Phillips, and S. Velicu, IEEE Trans. Electron Devices 58, 501 (2011).

4. S. Velicu, C.H. Grein, P.Y. Emelie, A. Itsuno, J.D. Philips, and P. Wijewarnasuriya, J. Electron. Mater. 39, 873 (2010).

5. M.A. Kinch, H.F. Schaake, R.L. Strong, P.K. Liao, M.J. Ohlson, J. Jacques, C.-F. Wan, D. Chandra, R.D. Burford, and C.A. Schaake, in Proceedings, Infrared Technology and Applications, vol. 7660 XXXVI, $76602 \mathrm{~V}$ (2010).

6. J. Piotrowski and A. Rogalski, Infrared Phys. Technol. 46, 115 (2004)

7. D. Lee, M. Carmody, E. Piquette, P. Dreiske, A. Chen, A. Yulius, D. Edwall, S. Bhargava, M. Zandian, and W.E. Tennant, J. Electron. Mater. 45, 4587 (2016).

8. P.C. Klipstein, et al., in Proc. SPIE, vol. 8704, 87041S (2013).

9. C. McMurtry, D. Lee, J. Beletic, A. Chen, R. Demers, M. Dorn, D. Edwall, C.B. Fazar, W. Forrest, F. Liu, A. Mainzer, J. Pipher, and A. Yulius, Opt. Eng. 52, 091804 (2014).

10. J. Caulfield, J. Curzan, J. Lewis, and N. Dhar, Proceedings of SPIE 9451, 94512F-1-9 (2015).

11. Y. Ozer and S. Kocaman, J. Appl. Phys. 122, 143103 (2017).

12. C.T. Elliott, Semicond. Sci. Technol. 5, 30 (1990).

13. T. Ashley and C.T. Elliott, Electron. Lett. 21, 451 (1985).

14. A.M. White, J. Cryst. Growth 86, 840 (1988).
15. K. Jóźwikowski, A. Jóźwikowska, M. Kopytko, A. Rogalski, and L.R. Jaroszewicz, Infrared Phys. Technol. 55, 98 (2012).

16. K. Jóźwikowski, M. Kopytko, and A. Rogalski, Opt. Eng. 50, 061003 (2011).

17. K. Jóźwikowski, A. Jóźwikowska, and M. Nietopiel, Opt. Quantum Electron. 49, 98 (2017).

18. K. Jóźwikowski, M. Kopytko, A. Rogalski, and A. Jóźwikowska, J. Appl. Phys. 108, 074519 (2010).

19. K. Jóźwikowski, M. Kopytko, and A. Rogalski, J. Electron. Mater. 41, 2766 (2012).

20. M. Kopytko and K. Jóźwikowski, IEEE Trans. Electron. Devices 62, 2278 (2015).

21. J. Piotrowski, A. Jóźwikowska, K. Jóźwikowski, and R. Ciupa, Infrared Phys. 34, 565 (1993).

22. W.W. Anderson, Infrared Phys. 20, 363 (1980).

23. E. Finkman and Y. Nemirovsky, J. Appl. Phys. 50, 4356 (1979).

24. Y. Yamamoto, Y. Miyamoto, and K. Tanikawa, J. Cryst. Growth 72, 270 (1985).

25. K. Jóźwikowski, A. Jóźwikowska, and A. Martyniuk, J. Electron. Mater. 45, 4769 (2016).

26. K. Jóźwikowski, Opt. Quantum Electron. 49, 101 (2017).

Publisher's Note Springer Nature remains neutral with regard to jurisdictional claims in published maps and institutional affiliations. 